\title{
O ensino e a pesquisa em filosofia da educação: um dilema histórico e uma alternativa contemporânea
}

\section{Teaching and research in philosophy of education: a historical dilemma} and a contemporary alternative

Fernanda Mota*

Universidade Federal do Piauí

Resumo $O$ presente artigo tem por objetivo investigar a questão relativa ao predomínio filosófico ou pedagógico no ensino da disciplina filosofia da educação e apresentar alguns aspectos de variantes propositivas de superação do referido dilema no âmbito do campo filosófico-educacional brasileiro contemporâneo. No intuito de contribuir para posteriores discussões sobre tal tema, bem como buscar novos sentidos para o ensino de Filosofia da Educação, nos amparamos em referenciais teóricos como: Albuquerque (1998; 2010), Tomazetti (2003; 2010), Valle; Kohan (2004), Tadeu e Kohan (2005), Gallo (2008), Pagni (2008; 2011; 2013), Deleuze; Guattari (2010), Deleuze (2010; 2011), dentre outros. Após a exposição do histórico dilema entre o domínio filosófico e o domínio pedagógico que permeia o ensino e a pesquisa no campo da filosofia da educação no Brasil, indicamos algumas recentes experimentações, inspiradas nos escritos de Gilles Deleuze e Michel Foucault, como uma alternativa para a superação desse problema.

PALAVRAS-CHAVE: Filosofia da educação; Ensino; Educação.

\begin{abstract}
The present article aims to investigate the issue of philosophical or pedagogical predominance in the teaching of the discipline of philosophy of education and to present some aspects of propositional variants of overcoming the aforementioned dilemma within the contemporary Brazilian philosophical-educational field. In order to contribute to further discussions on this topic as well as to seek new directions for the teaching of Philosophy of Education we are based in theoretical references that area such as: Albuquerque (1998; 2010), Tomazetti (2003; 2010), Valle; Kohan (2004), Tadeu e Kohan (2005), Gallo (2008), Pagni (2008; 2011; 2013), Deleuze; Guattari (2010), Deleuze (2010; 2011), among others. After exposing the historical dilemma between the philosophical domain and the pedagogical domain that permeates the teaching and research in the field of the philosophy of education in Brazil, we indicate some recent experiments, inspired by the writings of Gilles Deleuze and Michel Foucault, as an alternative to overcome this problem.
\end{abstract}

KEYWORDS: Philosophy of education; Teaching; Education. 


\section{Introdução}

Um dos temas mais recorrentes em torno do ensino (e pesquisa) no campo da filosofia da educação concerne a uma suposta e hierarquizada escolha entre dois domínios: o filosófico e o pedagógico. Assim, alguns professores enfatizam os aspectos filosóficos (de natureza mais teórica), outros enfatizam os aspectos pedagógicos (de natureza mais técnica e metodológica) como princípios norteadores para a sua concepção e prática de ensino de filosofia da educação. Em suma: a ênfase em um território em detrimento do outro.

Inversamente, podemos conceber a filosofia da educação de uma forma alternativa na qual sua característica mais expressiva é a função rizomática de conectar os territórios filosóficos e educacionais. Tarefa complexa porque religar provisoriamente ambos os platôs implica num mergulho através de eras na qual se busca não a reprodução linear da história da filosofia ou da educação, mas plataformas para a criação de novos conceitos (MOTA, 2014). Assim, a perspectiva deleuziana, longe de constituir um abandono aos textos clássicos, caracteriza-se como um forte apelo para retornarmos aos mesmos, pois se "todo conceito tem uma história", a criação de novos conceitos trará "pedaços ou componentes vindos de outros conceitos" (DELEUZE; GUATTARI, 2010, p.25-26). Dessa maneira, o estudo dos autores clássicos da filosofia da educação deve ser encarado "como um mergulho que traz sempre algo à luz" (DELEUZE, 2010, p.193).

Diante do exposto, o presente artigo tem por objetivo investigar a questão relativa ao predomínio filosófico ou pedagógico no ensino da disciplina filosofia da educação e apresentar alguns aspectos de variantes propositivas de superação do referido dilema no âmbito do campo filosófico-educacional brasileiro contemporâneo.

Dessa maneira, pretendemos enfatizar a relevância das filosofias da educação (no plural) de inspiração deleuzianas (e também foucaultianas) como propostas de sistemas conceituais abertos (rizomas) para o campo filosófico educacional brasileiro do século XXI.

\section{O dilema do ensino de filosofia da educação: entre o predomínio filosófico e o pedagógico}

Assim como ocorre no Brasil, a situação profissional dos docentes norte-americanos que trabalham com o ensino de filosofia da educação, também é contextualizada pelas discussões, delimitações e escolhas entre o lado filosófico e o pedagógico (MOTA, 2013). No que tange a questão do ensino de filosofia da educação, a similaridade entre a realidade educacional norte-americana e a brasileira nos cursos de Pedagogia e demais licenciaturas é evidenciada por fatores que remetem tanto aos estudantes quanto aos professores de filosofia da educação.

A respeito disso, Ericson (2000, p. 205) considera que a introdução de estudantes no campo da filosofia da educação é considerada um "problema incômodo" até para os professores mais experientes pelas seguintes razóes: a) a maioria dos estudan- 
tes de graduação e pós-graduação nos cursos de formação de professores chega até a disciplina filosofia da educação com "pouca preparação e base em filosofia como uma disciplina de investigação"; b) eles ainda apresentam pouco comprometimento com a disciplina porque "estão mais interessados na simples sobrevivência em salas de aulas e escolas"; c) suas impressões acerca da filosofia da educação é "uma mistura de apreensão e desdém" porque a referida disciplina é considera misteriosa, difícil e "inútil para ajudá-los a dominar os instrumentos de sobrevivência em sala de aula”. Nessa difícil tarefa de introdução ao estudo da filosofia da educação, Ericson (2000) sustenta ainda que tanto os autores quanto os professores, tem à sua disposição quatro estratégias pedagógicas: as três primeiras partem de uma abordagem histórica e a última possui uma abordagem não-histórica. Vejamos.

A primeira estratégia consiste em abordar a filosofia da educação como a história da filosofia da educação; a segunda estratégia trata a filosofia da educação como um embate entre correntes filosóficas: realismo, idealismo, empirismo, racionalismo, pragmatismo, etc.; a terceira estratégia é bastante similar a primeira, pois a filosofia da educação é apresentada historicamente, diferindo somente no acréscimo de uma revisão crítica das ideias à luz da contemporaneidade; e, a quarta estratégia considera a filosofia da educação a partir da apresentação de "problemas orientados ou conceitos orientados", nos quais as perspectivas de importantes figuras históricas são mencionadas à medida que suas análises ou considerações possam contribuir "para a questão ou conceito em discussão". Cada uma dessas estratégias apresenta limitações. (ERICSON, 2000, p. 206-208; TOMAZETTI, 2003, p.196-197).

$\mathrm{Na}$ primeira delas, após a exposição na sequência histórica, das ideias educacionais de um grande filósofo ou das ideias filosóficas de um grande educador, os estudantes são deixados por conta própria para avaliar a importância dessas ideias e fazer conexões com as suas futuras práticas em sala de aula.

$\mathrm{Na}$ segunda estratégia, o estudante é incitado a adotar uma corrente filosófica como sua filosofia da educação, mas ele corre o sério risco de simplesmente seguir acriticamente o 'ismo' preferido do professor da disciplina para, em seguida, tentar extrair da referida corrente teórica eleita, implicações relevantes para a sua prática.

$\mathrm{Na}$ terceira delas, o estímulo ao exercício da crítica, seria um fator positivo se não esbarrasse no problema geral da falta de interesse por questões teóricas, ou seja, os estudantes têm interesses específicos sobre instrumentos para a prática em sala de aula e não sobre os pressupostos filosóficos que embasam as teorias pedagógicas e fundamentam a prática.

A quarta estratégia, preferida pelo autor, teria a vantagem de não se limitar previamente pela falta de interesse generalizada dos estudantes, pois qualquer tópico ou problema destacado por eles seria amplamente analisado pelo referencial filosófico, numa demonstração de abrangência e praticidade. Todavia, nessa abordagem, mais do que nas anteriores a ênfase filosófica reduz a educação a um papel praticamente inexistente, visto que seu foco está "no poder dos métodos de análise filosóficos, não meramente para fazer filosofia, mas também como um modo de pensamento que pode ser aplicado utilmente a todas as facetas da vida" (ERICSON, 2000, p. 208). Esta 
última estratégia denota uma forte influência do pragmatismo e da filosofia analítica, tipos de filosofia praticada respectivamente por americanos e ingleses.

No Brasil, as três primeiras estratégias predominam e a quarta estratégia é quase inexistente, pois a filosofia da educação pragmatista professada por Anísio Teixeira (1978) não prosperou e a filosofia analítica da educação não chegou a ser considerada de forma apropriada.

Se, entre os anos de 1950 e 1970, nos países de língua inglesa o pragmatismo e a filosofia analítica dividiam a preferência como orientação teórica norteadora para a filosofia da educação, no Brasil, isso nunca ocorreu na mesma proporção. Por um lado, devido às críticas que outras tradições filosóficas já estabelecidas no cenário brasileiro fizeram às tendências filosóficas anglo-saxãs. Por outro lado, devido a fatores específicos ocasionados pelo contexto político ditatorial vivenciado pelo país entre 1964 e 1985.

Sobre os fatores que contribuíram para dificultar o projeto de Anísio Teixeira de implantação de uma filosofia da educação democrática, nos moldes do pragmatismo deweyano, Pagni (2008) explica que o ensino da referida disciplina sempre permaneceu alicerçado em uma forte influência europeia.

Independente da formação ou não em Filosofia, o ensino dessa disciplina pelos catedráticos oscilava entre a história da filosofia e das ideias pedagógicas, o tratamento de alguns temas da filosofia e das ciências da educação e a pregação de uma doutrina que fundamentasse a prática pedagógica dos professores. Pode-se dizer, ainda, que o ensino de filosofia da educação nos cursos de Filosofia ou de Pedagogia tinha por referência a historiografia da filosofia e os manuais de pedagogia europeus, principalmente, franceses e alemães, com forte resistência à filosofia inglesa e americana (PAGNI, 2008, p. 98-99).

Ao considerarmos as quatro estratégias de ensino mencionadas por Ericson (2000), vemos que a filosofia educacional proposta por Anísio Teixeira foi concebida como uma via intermediária entre a abordagem histórica e a não histórica. Isso porque, ele enfatizou a importância dos estudos históricos da filosofia e da educação, coadunados com um papel interventor da filosofia da educação, cujo ensino deveria garantir aos seus estudantes a possibilidade refletir e propor alternativas tanto sobre problemas oriundos da prática docente quanto de problemas procedentes da vida contemporânea (PAGNI, 2008).

Assim como ocorreu em relação à filosofia da educação pragmatista de Anísio Teixeira, também a filosofia da educação analítica foi alvejada pelas críticas feitas a partir das correntes filosóficas de origem francesa e alemã. Tais críticas à filosofia analítica alegavam que sua abordagem era uma prática meramente técnica (a análise e elucidação conceitual), que seus pressupostos cientificistas (objetividade, neutralidade e racionalidade) a deixavam alheia às questões educacionais de ordem prática, nas diversas instâncias políticas e sociais. 
A obra mais representativa dessa vertente no campo educacional é Educação e Linguagem, organizado por José Mario Pires Azanha (1931-2004), com colaborações de Jorge Nagle e Carlos Eduardo Guimarães, entre outros. O referido livro não foi bem recebido pelos educadores menos por divergências teóricas e mais por questões políticas, já que Nagle e Azanha eram considerados intelectuais ligados ao governo ditatorial. Independentemente dos motivos que inviabilizaram a filosofia analítica da educação no Brasil, naquela época, Guimarães (1976, p.105) propôs que a filosofia da educação abdicasse de seu caráter informativo baseado nas abordagens históricas em prol de um "ensino que envolva, por parte do aluno, a aquisição de hábitos e normas do pensamento crítico". Tais habilidades seriam desenvolvidas e exercitadas, principalmente pelo contato dos alunos com o domínio docente das ferramentas lógicas a partir das quais são feitas as análises dos principais termos, conceitos e teorias da linguagem educacional.

Tomazetti (2010) elogia tal iniciativa de revisar antigos modelos de ensino de filosofia da educação e recorda que as antigas formas de ensinar são encontradas ainda hoje tanto nos cursos das Escolas Normais, quanto nos cursos de Pedagogia e demais licenciaturas. Embora suas considerações contemplem o ensino do professor de filosofia da educação na Escola Normal, resguardadas as devidas diferenças, acreditamos que a mesma tensão entre o predomínio filosófico e o pedagógico, decorrentes de formações iniciais distintas, pode ser verificada entre professores que atuam no ensino superior.

É necessário lembrar que o professor de Filosofia da Educação na Escola Normal, quase sempre é oriundo de cursos de Pedagogia ou de outra área das Ciências Humanas e não propriamente de um Curso de Filosofia. Neste caso, muitas vezes, há dificuldades em construir as relações efetivas entre filosofia e educação, podendo-se cair em debates ou afirmações vagas e distantes da atividade filosófica. Todavia, quando o professor tem formação inicial em Filosofia, há também dificuldades, pois este raramente possui um envolvimento significativo com o campo educacional em geral, podendo, muitas vezes, transformar a aula em um momento de erudição filosófica, distante das questões educacionais e, por conseguinte, dos problemas que os estudantes se colocam ou deveriam se colocar na condição de futuros professores de crianças (TOMAZETTI, 2010, p.51).

No mesmo período em que a identidade e o objeto de estudo da filosofia da educação eram temas das discussões anuais do GT - Filosofia da Educação da ANPED, Guarde (1998) investigou a questão da identidade disciplinar da filosofia da educação e chegou a um prognóstico bastante pessimista. Na sua pesquisa, após analisar os programas e depoimentos de professores de filosofia da educação da rede privada da cidade de São Paulo, o autor concluiu que "a disciplina Filosofia da Educação é terra de ninguém", pois cada professor "sente-se absolutamente à vontade para elaborar do seu jeito o modo como ela deve ser ministrada" (GUARDE, 1998, p. 140). Esse quadro desolador enfatizava que a precária prática dos referidos professores em sala de aula, era resultado de um contexto bastante comum nas instituições particulares que constituíram o campo da pesquisa: a inexistência de qualquer tipo de interferência 
institucional sobre o planejamento e o ensino da disciplina filosofia da educação; a elaboração estritamente pessoal dos programas; a ausência de diálogos com outros profissionais da mesma área; e, a escassez de bibliografias de referência.

Nessa discussão, Albuquerque (1998) considera que a questão da formação do professor de filosofia da educação deve ser evidenciada porque aquilo que os autores afirmam a respeito da filosofia da educação e a maneira como ela é trabalhada pelos professores em sala de aula, decorre da influência preponderante recebida em seus cursos originais, algo que pode ser constatado na "forma como a literatura conduz a discussão desta disciplina, como também nos conteúdos que propõe para serem ensinados". Diante desse quadro, a relevância, seleção e tratamento dos conteúdos disciplinares da filosofia da educação "parece ser definida muita mais em função da "familiaridade" que o professor tem com o seu curso de origem (ALBUQUERQUE, 1998, p.56). De modo que, a necessidade de transitar entre o pensamento filosófico e o educacional, combinada com a escassez de recursos institucionais (cursos e material bibliográfico específicos da área), faz com que o professor de filosofia da educação, no contexto do ensino de sua disciplina, trabalhe conteúdos diretamente relacionados aos conhecimentos oriundos da sua formação inicial ou continuada.

Tal opinião é compartilhada por Valle e Kohan (2004), que também sustentam que a formação docente constitui um fator relevante na determinação do tipo de prática profissional adotada pelos professores que atuam com a disciplina filosofia da educação. $\mathrm{Na}$ concepção desses autores, a formação acadêmica recebida pelos professores nos seus cursos de origem implica na determinação do tipo de abordagem trabalhada por eles na disciplina em questão, resultando em tratamentos irregulares concedidos à filosofia ou à educação. Assim, as situações vivenciadas nas graduações em filosofia, pedagogia, ciências sociais ou em qualquer outra área tendem a se reproduzir nas pós-graduações em filosofia e educação, nas quais a filosofia da educação é concebida e ensinada de forma heteróclita.

Assim, vindos de trajetórias que guardam, entre si, pouquíssimos pontos de contato, os professores tendem naturalmente a moldar seus próprios cursos de filosofia da educação, de acordo com suas experiências individuais, como uma introdução à lógica ou à epistemologia, à história da filosofia ou à história das ideias filosóficas sobre a educação, ou ainda como um longo estudo monográfico de um autor ou de uma corrente do pensamento educacional - sob o risco de reduzirem sua atuação à transmissão de uma filosofia doutrinária da educação (VALLE; KOHAN, 2004, p.17).

Desse modo, a formação do professor de filosofia da educação constitui um dos principais fatores na construção dos processos de desenvolvimento da disciplina filosofia da educação, que tenderá a privilegiar os conteúdos filosóficos ou pedagógicos, dependendo dos tipos de conhecimentos predominantemente internalizados pelo professor ao longo de sua formação. Tal constatação denota que, respectivamente, os pressupostos teórico-metodológicos recebidos em uma formação filosófica ou em uma formação pedagógica resultam, na prática, em um fechamento cognitivo expresso na ênfase demasiada nos conteúdos filosóficos em detrimento dos assuntos pedagógicos, no primeiro caso; ou na ênfase demasiada nos conteúdos pedagógicos em detrimento 
dos assuntos filosóficos. Diante desse impasse, ressaltamos que nosso entendimento é favorável ao diálogo entre a Educação e a Filosofia, e contrário à sujeição de uma sobre a outra.

A autora complementa os resultados de sua investigação com a advertência que seu trabalho, realizado originalmente no ano de 1998, tentou provocar um debate no campo filosófico educacional que "tem tido pouco investimento intelectual entre os filósofos da educação: o do seu ensino" (ALBUQUERQUE, 2003, p. 4). Essa perspectiva é corroborada pelo fato que, embora a reunião do GT - Filosofia da Educação, realizada em 1997 houvesse determinado que os temas norteadores das reuniões dos dois anos subsequentes deveriam versar respectivamente sobre as questões acerca da "Identidade da Filosofia da Educação" e do "Ensino da Filosofia da Educação", o ano de 1999 registrou apenas dois trabalhos, num total de doze, que efetivamente focalizaram o ensino da disciplina filosofia da educação.

Pagni (2008), por sua vez, elucida que o estado atual da pesquisa e do ensino de filosofia da educação é resultado da autonomização das ciências da educação e da própria Filosofia. Como vimos no início do presente capítulo, a transição da pedagogia de disciplina para ciência da educação foi acompanhada por uma relativa desvinculação com a teoria filosófica, considerada alheia aos problemas da prática escolar cotidiana, e por uma aproximação crescente com disciplinas como a sociologia, a psicologia, a didática e outras técnicas de ensino, que por serem consideradas matérias práticas e instrumentais, seriam capazes de oferecer o suporte necessário para as exigências formativas profissionais docentes. Já a autonomização da Filosofia na esfera acadêmica, tanto em relação à produção teórica quanto ao seu ensino, ocorreu a partir da centralização das discussões em torno de temas filosóficos clássicos, da história da filosofia, da chamada filosofia pura e de outras áreas filosóficas consideradas importantes como a filosofia da ciência e a filosofia política.

Como consequência desses dois fatores, a filosofia da educação defrontouse com problemas originados em ambas as vertentes. Pelo lado educacional, em virtude do problema da relação teoria e prática nos cursos de formação de professores, a disciplina filosofia da educação viu-se no impasse entre ensinar a história da filosofia da educação ou estimular a reflexão filosófica sobre temas educacionais emergenciais, sendo que cada abordagem era considerada, respectivamente, insuficientemente prática e superficialmente teórica. Pelo lado filosófico, a disciplina filosofia da educação não teve muito reconhecimento, pois foi renegada devido ao seu não pertencimento ao campo filosófico ou descaracterizada por pesquisadores e professores da área que, em suas discussões ou aulas, terminavam "preconcebendo a filosofia da educação como uma discussão filosófica de segunda categoria, por ser muito mais atinente à discussão pedagógica, em seu sentido estrito de discussão didática sobre métodos e técnicas de ensino" (PAGNI, 2010, p. 101).

No âmbito dessa discussão evidencia-se o fato que distintas orientações teóricas produzem diferentes concepções de filosofia da educação e, consequentemente, diferentes práticas de ensino (MARINHO, 2012). Tal quadro torna-se ainda mais complexo quando consideramos a diversidade da formação inicial e continuada dos professores que atuam no campo da filosofia da educação. Isto porque, ainda que seja 
possível encontrar profissionais detentores das mais diversificadas formações, a maioria é formada em pedagogia ou filosofia, ou em ambos os cursos, ou ainda, têm graduação em pedagogia com pós-graduação em filosofia, ou graduação em filosofia com pós-graduação em educação (TOMAZETTI, 2003; HENNING, 2010).

Se considerarmos que a formação (graduação e pós-graduação) do professor de filosofia da educação não é consensual, resta saber como e até que ponto esta formação diversificada pode implicar em compreensões distintas do lugar e função do campo da Filosofia da Educação no curso de pedagogia e outras licenciaturas, consequentemente, como tal enfoque teórico-metodológico distinto orienta a sua prática em sala de aula, afetando assim a sua contribuição à formação do pedagogo e dos demais professores formados em outros cursos.

\section{Uma alternativa para o ensino e pesquisa de filosofia da educação}

Diante do exposto até aqui, é possível constatar que nos dias atuais, o campo da filosofia da educação continua permeado pelo antigo dilema que faz com que teóricos, pesquisadores e professores tenham que eleger a vertente filosófica ou a pedagógica como predominantes tanto na formulação de sua concepção de filosofia da educação quanto para o seu ensino. Em ambos os casos, persiste uma indesejável priorização de uma área em detrimento de outra.

Não obstante, tais questões constituem importantes lacunas na literatura especializada acerca da formação docente, visto que são escassos os estudos acerca da prática de ensino dos professores de filosofia da educação no Brasil.

Diante desse impasse, como conceber a filosofia da educação e como praticar seu ensino sem cair nas mesmas armadilhas das tendências vigentes?

Para tentar responder essa questão, podemos destacar brevemente as interessantes contribuições teóricas de autores como Tadeu e Kohan (2005), Gallo (2008) e Pagni $(2011,2013)$ que, na contemporaneidade, produzem versões distintas e complementares de filosofia da educação a partir do legado dos filósofos franceses Deleuze e Foucault. Em suas respectivas conexões, temas relevantes da realidade escolar brasileira são perspectivados pela filosofia da educação sem, no entanto, cair no falso dilema entre a vertente filosófica e a vertente pedagógica.

Tadeu e Kohan (2005) criticam a concepção tradicional e o ensino habitual de filosofia da educação no Brasil, baseados na história das ideias filosóficas sobre a educação ou na história das ideias pedagógicas a partir de algum filósofo e sugerem que é possível praticar outro tipo de filosofia da educação.

[...] pensamos que pode ser feita uma outra filosofia da educação: ato filosófico e não histórico, pensamento que pensa e não apenas mimetiza o que outros pensaram. Como filosofia, ela é múltipla, diversa, aberta. Não está acima nem abaixo de nada ou de ninguém. É um movimento, um gesto, uma possibilidade do pensar (TADEU; KOHAN, 2005, p.1172). 
Essa nova perspectiva sobre a filosofia da educação seria inspirada pelas ideias de Deleuze, que propôs que o movimento do filósofo (da educação ou de qualquer outro campo) "tem a ver com traçar planos, colocar problemas e criar conceitos", pois sempre há espaços "para criar o que ainda não foi criado, para pensar o que ainda não foi pensado” (TADEU; KOHAN, 2005, p. 1172-1173).

Por sua vez, Gallo (2008) considera que profissional do campo da filosofia da educação deve também revestir-se da condição de criador de conceitos. Nessa perspectiva, a ressalva a ser feita entre o filósofo da educação e os demais filósofos dedicados a outros campos do conhecimento, é que sua atividade deve se caracterizar pela imersão no âmbito do território da Educação. Nas suas palavras:

Se o que importa é resgatar o filósofo criador (de resto, a única possibilidade para que ele seja filósofo), então o filósofo da educação deve ser aquele que cria conceitos e que instaura um plano de imanência que corte o campo de saberes educacionais. Uma filosofia da educação, nessa perspectiva, seria resultado de uma dupla instauração, um duplo corte: o rasgo no caos operado pela filosofia e o rasgo no caos operado pela educação. Ela seria resultante de um cruzamento de planos: plano de imanência da filosofia, plano de composição da educação enquanto arte, múltiplos planos de prospecção e de referência da educação enquanto ciências(s). (GALLO, 2008, p.57).

Dessa maneira, o filósofo da educação é identificado não somente pela transição que ele efetua entre os territórios da filosofia e da educação, mas, sobretudo, pela ênfase por dedicada aos problemas educacionais que o afetam diretamente e que são por ele, pensados filosoficamente. Nesta condição, o filósofo da educação não se fixa em apenas um território, mas executa constantes movimentos de desterritorialização e reterritorialização, transitando livremente entre os diversos saberes provenientes dos campos da Filosofia e da Educação (GALLO, 2008).

Finalmente, na acepção de Pagni (2011), a complexa dificuldade de articulação entre as áreas acadêmicas da filosofia e da educação pode ser superada sem que uma seja priorizada em prejuízo da outra. Nessa acepção, a filosofia da educação não abdicaria da função de propiciar saberes "saberes filosófico educacionais", mas a complementaria com a tarefa de compartilhar junto aos discentes "outros saberes (científicos, literário, artísticos, etc.) que auxiliassem na compreensão do ethos e da multiplicidade cultural na qual se formam" (PAGNI, 2013, p. 126). Em linhas gerais, o propósito dessa filosofia da educação ad hoc, como arte da superfície, é assim descrito:

[...] significa adotar uma perspectiva de que o núcleo do sujeito não é natureza bárbara que age pela força, desde as entranhas da terra, tampouco o espírito que representou o progresso e a civilização, das alturas da razão, mas a transformação de si na relação com o outro. Esse outro, mais do que objeto ou simples problema, é alguém que, imerso em seu ethos, carrega consigo a sua inscrição, ajustando-se e resistindo ao existente, dando mobilidade a um devir que não se reduz ao pessoal, mas é social e histórico (PAGNI, 2011, p. 165).

Nessa perspectiva, a filosofia da educação não estaria situada nem nas alturas das teorizações e nem nas profundezas da técnica, mas na superfície, situada entre ambas. Desse modo, a filosofia da educação seria compreendida e praticada como uma 
arte de superfície, uma disciplina que além de seu papel acadêmico na formação de professores, também constituiria um campo fértil para a produção de experiências e o cultivo de práticas de si (PAGNI, 2011; 2013).

\section{Considerações finais}

A constatação que a filosofia da educação continua transpassada pelo antigo dilema entre a priorização dos aspetos teóricos ou dos aspectos práticos, representados respectivamente, pelos domínios da filosofia e da pedagogia não constitui um impedimento para o surgimento de alternativas para o seu ensino e pesquisa. Dessa forma, indicamos que a celeuma entre o predomínio filosófico ou pedagógico não pode ser encerrada nos moldes tradicionais, ou seja, com a derradeira determinação de uma vertente principal e que, não obstante, relegaria a vertente remanescente à uma condição meramente ancilar.

Diante desse impasse, apontamos para um caminho alternativo para o ensino e pesquisa de filosofia da educação. Essa indicação não é a única alternativa teórica no campo investigativo da filosofia da educação brasileira contemporânea. Entretanto, conforme sustentamos no decorrer do artigo, encerra variantes bastante promissoras no que se refere à ampliação dialógica entre os referidos domínios e também entre outras áreas do saber. Esse tipo de filosofia da educação não é unívoco, embora parta de aportes teóricos comuns, a saber, o referencial da filosofia francesa contemporânea, representada principalmente, por Gilles Deleuze e Michel Foucault. Desse modo, são emblemáticas as experimentações de Tadeu e Kohan (2005), Gallo (2008) e Pagni (2011, 2013) que, no início do século XXI, se recusaram a empenhar seus passos nos rígidos caminhos dos territórios filosófico ou pedagógico e abriram novas trilhas para aqueles pretendem se aventurar na indissociável jornada filosófica educacional da pesquisa e da docência.

\section{Referências}

ALBUQUERQUE, M. B. B. O ensino da filosofia da educação em questão. Revista Sul-Americana de Filosofia e Educação. Brasília, n. 1, nov. 2003.

. Filosofia da educação: uma disciplina entre a dispersão de conteúdos e a ausência de identidade. Perspectiva, Florianópolis, v. 16, n. 29, jan/jun, p. 45-61. 1998.

DELEUZE, G. Conversações. São Paulo: Editora 34, 2010.

DELEUZE, G.; GUATTARI, F. O que é a filosofia? 3. ed. Trad. Bento Prado Jr. e Alberto Alonso Muñoz. São Paulo: Editora 34, 2010.

ERICSON, D. P. Orientação para a filosofia da educação: localizando o campo de atuação em relação a novos públicos. In: GHIRALDELLI JR., P. (Org.). O que é filosofia da educação? 2 ed. Rio de Janeiro: DP\&A. p.205-223, 2000.

GALLO, S. Deleuze e a Educação. Belo Horizonte: Autêntica, 2008.

GUARDE, S. Concepções teóricas e práticas pedagógicas no ensino de filosofia da educação: elementos para a discussão de sua identidade. Dissertação (Mestrado em Educação). Centro Universitário Salesiano, São Paulo-SP, 1998.

GUIMARÃES, C. E. Filosofia, lógica e educação. In: NAGLE, J. (Org.). Educação e Linguagem. São Paulo: Edart. 1976. 
HENNING, L. M. P. Pesquisa filosófica na educação: a formação do pesquisador e a sua contribuição no campo educacional. In: HENNING, L. M. P. (Org.). Pesquisa, ensino e extensão no campo filosófico educacional: possibilidades presentes no contexto universitário. v. 1. Londrina: EDUEL, 2010

MARINHO, C. M. A filosofia da diferença de Gilles Deleuze na filosofia da educação no Brasil. Relatório final (Pós-doutorado em Educação). Universidade Estadual de Campinas, Campinas-SP, 2012.

MOTA, F. A. B. da. Entre a Educação e a Filosofia: aspectos históricos da filosofia da educação como disciplina acadêmica e como campo de investigação. Revista da FAEEBA - Educação e Contemporaneidade, Salvador, v. 22, n. 39, p. 19-30, jan/jun. 2013.

A formação e a prática de ensino dos professores de filosofia da educação a partir de Deleuze e Guattari: a formação de conceitos e a desterritorialização. Dialogia, São Paulo, n. 19, p. 131-145, jan/jun. 2014.

PAGNI, P. Â. Anísio Teixeira - Experiência reflexiva e projeto democrático: a atualidade de uma filosofia da educação. Petrópolis: Vozes, 2008.

Entre a modernidade educacional e o modernismo: um ensaio sobre a possibilidade de uma Filosofia da Educação como arte da superfície. In: SEVERINO, A. J.; ALMEIDA, C. R. S.; M. A. LORIERI (Orgs.). Perspectivas da Filosofia da Educação. São Paulo: Cortez Editora, 2011.p. 150-166.

A pesquisa e o ensino no campo da Filosofia da Educação: críticas e possibilidades. In: GUEDES, N. C.; ARAÚJO, H. M. L.; IBIAPINA, I. M. L. M. Pesquisa em Educação: contribuições ao debate na formação docente. v. 1. Teresina: EDUFPI, 2013. p. 111-146.

TADEU, T.; KOHAN, W. Apresentação - Dossiê “Entre Deleuze e a Educação". In: Revista Educação e Sociedade, Campinas, vol. 26, n. 93, p. 1171-1182, set./dez. 2005.

TEIXEIRA, A. Pequena introdução à filosofia da educação. São Paulo: Editora Nacional, 1978.

TOMAZETTI, E. M. Filosofia da educação: um estudo sobre a história da disciplina no Brasil. Ijuí: Unijuí, 2003.

. O ensino de filosofia da educação na escola normal. In: HENNING, L. M. P. (Org.).

Pesquisa, ensino e extensão no campo filosófico educacional: debate contemporâneo sobre a educação filosófica. v. 2. Londrina: EDUEL, 2010.

VALLE, L.; KOHAN, W. O. Notas para pensar a filosofia da educação no Brasil. Educação em Revista, v. 1, n. 5, p. 15-22, 2004.

* Professora doutora da Universidade Federal do Piauí, Teresina, Piauí. Brasil.

\section{Correspondência}

Fernanda Mota - Universidade Federal do Piauí, Centro de Ciências da Educação. Campus Universitário Ministro Petrônio Portella, Ininga. CEP: 64049-550. Teresina, Piauí, Brasil.

E-mail: fabmota13@yahoo.com.br

Recebido em 07 de dezembro de 2016

Aprovado em 22 de março de 2017 
